1. Caracterização regional; 2. O povoamento;

3. A atividade industrial;

4. O empresario industrial; 5. Conclusão.

François E. J. de Bremaeker *

\footnotetext{
*Assessor técnico especial do Centro de Pesquisas Urbanas do Instituto Brasileiro de
} Administração Municipal (IBAM); membro.da Comissão

Arquidiocesana de Pastoral Social da Arquidiocese do Rio de Janeiro; membro do Grupo de

Trabalho designado para promover a implantação do Centro de Informação e Documentação sobre Administração Local e Urbana (CIDAL) do IBAM.

\section{CARACTERIZAÇĀO REGIONAL}

A região do sudoeste paranaense tem como limites o rio Iguaçu ao norte, o território da Repúbliça Argentina a oeste, a porção ocidental do estado de Santa Catarina ao sul, e os municípios de Mangueirinha e Clevelândia, exteriores à regiăo, como limite oriental. E constituida por 24 municipios ${ }^{1}$ que somam uma área equivalente a $11.622 \mathrm{~km}^{2}$.

Sua população em 1960 era de 228.923 habitantes, enquanto que em 1970 seu efetivo praticamente dobrou, apresentando 446.360 habitantes. Isso representa dizer que o crescimento demográfico se processou à base de $6,9 \%$ ao ano. Em 1975, segundo estimativas da Fundação IBGE, a região deveria estar abrigando 569.317 habitantes, - que lhe perfaz uma densidade demográfica de aproximadamente 49 habitantes por $\mathrm{km}^{2}$.

\section{OPOVOAMENTO}

A característica fundamental do sudoeste paranaense, que o distingue de muitas outras regióes do País, é a de ser uma região colonial de povoamento recente. Os colonos que habitam a regiăo são pequenos agricultores de origem européia que se dedicam, em geral, à policultura.

Fiel ao gênero de vida agrícola, esta populacão veio-se deslocando sempre em busca de novas terras, através de sucessivas migraçőes. De origem italiana e alemã, principalmente, ocupou inicialmente a região do Alto Uruguai, no Rio Grande do Sul, do vale do rio do Peixe e do oeste catarinense, penetrando finalmente no sudoeste paranaense, regiăo ainda vazia ou esparsamente povoada - dois habitantes por $\mathrm{km}^{2}$ - em 1940 , onde viviam pessoas de origem cabocla, que subsistiam da caça e da criação de porcos.

O povoamento do sudoeste paranaense se processou pela ocupação espontânea, na qual o colono comprava o direito de posse do caboclo, ou simplesmente instalava-se numa área vazia, sendo a mediç̃̃o e legalização de sua glaba realizada posteriormente. Processava-se também a ocupacão, mediante colonização oficial e de empresas particulares.

A diferença de outras regióes coloniais do Rio Grande do Sul e de Santa Catarina, o sudoeste paranaense caracteriza-se pelo seu povoamento recente, e este caráter aparece, entre outros aspectos, através da pouca expressão da atividade industrial e de uma vida urbana de implantação muito recente. Em 1970, a participação da população urbana no contexto regional, definida censitariamente como a sede administrativa dos municípios e dos distritos (cidades e vilas), não ia além dos $18 \%$ da população total. 


\section{A ATIVIDADE INDUSTRIAL}

A atividade industrial do sudoeste paranaense apresenta um pequeno contingente de mão-deobra empregada: 4.631 pessoas em 1970, em 667 estabelecimentos industriais. Esta população empregada corresponde a $1,04 \%$ da população regional e a 3,01\% da população economicamente ativa regional.

O pequeno efetivo de mão-de-obra, que se distribui quase que uniformemente pela região em pequenas e recentes serrarias e moinhos - que representam mais de $80 \%$ dos estabelecimentos industriais - e a sua localização sobretudo no meio rural e nas vilas, são as características que traduzem a pouca expressão da atividade industrial no sudoeste paranaense.

Tais caracteristicas correlacionam-se ao caráter recente do povoamento regional, onde o estágio de evolução industrial é o do beneficiamento primário dos produtos regionais. Devido à insuficiência de capitais, os estabelecimentos madeireiros se dedicam sobretudo à preparação do produto mais elementar - as pranchas de madeira - sendo pequeno e inexpressivo o número de estabelecimentos de laminação e compensados, e inexistentes os de produção de celulose e papel.

Esta mesma característica se manifesta em relação às indústrias de produtos alimentares, que se apoiam na moagem de cereais em moinhos coloniais. Inexistem frigoríficos que industrializem 0 importante rebanho suíno regional e, só em 1968 começou a funcionar a primeira fábrica de óleo de soja, assim mesmo, produzindo oleo bruto, sem qualquer processo de refinação.

As indústrias dos demais gêneros produzem bens de consumo, que se destinam basicamente ao mercado regional, não sendo vendidos no mercado da região sul e muito menos no mercado nacional.

\section{O EMPRESARIO INDUSTRIAL}

Uma vez caracterizada a atividade industrial do sudoeste paranaense, podemos melhor compreender a debilidade do capital e conhecer a figura do empresário e, paralelamente, a gênese deste capital.

No sudoeste paranaense, a figura do empresário desempenha um importante papel, visto ser este empresário o elemento responsável pela captação e pela aplicação do capital. Em quase todos os estabelecimentos o capital é originário da própria região, tendo, portanto, nascido do esforço, da poupança e do investimento regional.

O empresário é aquele que, em nome próprio ou de seus sócios e/ou familiares, dirige uma em- presa, inovando e promovendo a acumulação do capital. Na maior parte dos casos, o empresário fundou e acompanha o desenvolvimento de sua empresa.

a) Origem étnica - Etnicamente, uma grande parte dos empresários é de origem italiana, seguidos de longe pelos de origem alemã, brasileira e, residualmente pelos de origem polonesa, portuguesa, israelense, holandesa e suíça. Podemos avaliar a importância destes grupos étnicos por meio da tabela 1, constituída com o resultado de pesquisa em mais da quinta parte dos estabelecimentos da região.

Tabela 1

Distribuição dos empresários entrevistados segundo a origem étnica - 1968

\begin{tabular}{l|r|r}
\hline \multirow{2}{*}{ Origem étnica } & \multicolumn{2}{|c}{ Empresários } \\
\cline { 2 - 3 } & Numero & $\%$ \\
\hline & & \\
Total & 163 & 100,0 \\
Italiana & 98 & 60,1 \\
Alemã & 33 & 20,3 \\
Brasileira & 22 & 13,5 \\
Outras & 10 & 6,1 \\
\hline
\end{tabular}

b) Origem geográfica - A exemplo da relação existente entre a etnia do empresariado e a da população regional, temos uma grande semelhança no que diz respeito à origem geográfica dos empresários industriais, que migraram dos dois estados mais ao sul do país para o Paraná, e em especial para a região estudada. Este fato pode ser observado com o auxílio da tabela 2.

Tabela 2

Distribuição dos empresários entrevistados segundo a origem geográfica - 1968

\begin{tabular}{l|r|r}
\hline \multirow{2}{*}{ Origem geográfica } & \multicolumn{2}{|c}{ Empresários } \\
\cline { 2 - 3 } & NGmero & $\%$ \\
\hline \multirow{2}{*}{ Total } & 163 & 100,0 \\
Rio Grande do Sul & 95 & 58,4 \\
Santa Catarina & 34 & 20,8 \\
Paraná & 29 & 17,7 \\
São Paulo & 5 & 3,1 \\
\hline
\end{tabular}

c) Origem social - A origem social dos empresários industriais, se baseada na análise da profissão exercida pelos seus pais, acusaria uma ligação bastante Intima com o meio rural. Grande parte deles era lavrador, tanto no Rio Grande do Sul a maioria - como em Santa Catarina.

Com o auxflio da tabela 3 , poderemos ter uma idéia da origem social dos empresários, segundo grupos de atividades correlatas, levantadas para um total de 102 casos. 
Tabela 3

Atividade profissional exercida pelos pais dos empresários industriais - 1968

\begin{tabular}{|c|c|c|c|c|}
\hline \multirow{2}{*}{ Atividades profissionais } & \multicolumn{2}{|c|}{ Námero de casos } & \multicolumn{2}{|c|}{$\%$} \\
\hline & Atividades & $\begin{array}{l}\text { Grupos de } \\
\text { atividades }\end{array}$ & Atividades & $\begin{array}{l}\text { Grupos de } \\
\text { atividades }\end{array}$ \\
\hline $\begin{array}{l}\text { Lavoura } \\
\text { Lavoura e pecuária } \\
\text { Lavoura e comercio } \\
\text { Pecuária }\end{array}$ & $\begin{array}{r}58 \\
4 \\
1 \\
2\end{array}$ & 65 & $\begin{array}{r}56,8 \\
3,9 \\
1,0 \\
2,0\end{array}$ & 63,7 \\
\hline $\begin{array}{l}\text { Combrcio } \\
\text { Hotelarla }\end{array}$ & $\begin{array}{r}20 \\
2\end{array}$ & 22 & $\begin{array}{r}19,6 \\
2,0\end{array}$ & 21,6 \\
\hline $\begin{array}{l}\text { Industrial } \\
\text { Funcionário público / Profissional liberal }\end{array}$ & $\begin{array}{l}7 \\
2\end{array}$ & 9 & $\begin{array}{l}6,8 \\
2,0\end{array}$ & 8,8 \\
\hline $\begin{array}{l}\text { Carpinteiro } \\
\text { Pedreiro e seleiro }\end{array}$ & $\begin{array}{l}4 \\
1\end{array}$ & 5 & $\begin{array}{l}3,9 \\
1,0\end{array}$ & 4,9 \\
\hline Operário em serraria & 1 & 1 & 1,0 & 1,0 \\
\hline
\end{tabular}

Praticamente $2 / 3$ dos pais dos atuais empresários estavam vinculados ao meio rural, desenvolvendo atividades agropastoris, havendo apenas um caso em que era executada a atividade agrícola em conjunto com a comercial. $O$ que vale entretanto ressaltar é que 9 entre 10 dos pais ligados a estas atividades correlatas se dedicavam exclusivamente à lavoura.

Em segundo plano, com pouco mais da quinta parte dos casos, aparecem as atividades ligadas ao setor terciário da economia onde o comércio praticamente monopoliza esta categoria.

Apenas $6,8 \%$ dos pais dos empresários se dedicavam às atividades industriais, como industriais. Nesta categoria de atividades correlatas, foram incluídos os funcionários públicos e profissionais liberais, tendo em vista o maior status da sua ocupação.

Em quarto e último lugar, estão colocados os $5,9 \%$ restantes dos pais que desenvolviam atividades de certo grau de especialização e operários (um caso).

Observa-se, pois, que muito pouca influência pode exercer na escolha da atual profissão dos empresários industriais a atividade desenvolvida pelos seus pais.

d) A primeira ocupação - Ao migrarem para o sudoeste paranaense, estes, que viriam a ser os atuais empresários, por muitas vezes não exerceram tal função logo de início. Foi o caso daqueles que continuaram vinculados à lavoura - maior percentual - ou que não ousaram logo de início implantar uma indústria, limitando-se por vezes a exercer os mesmos ofícios que em sua terra de origem.
Podemos observar, com o auxílio da tabela 4, que muito embora as atividades ligadas à agropecuária sejam as mais exercidas como primeira ocupação do empresário, sua participação decaiu sensivelmente em relação à profissão exercida pelo seu pai. As atividades agropecuárias são exercidas por quase $40 \%$ dos empresários, sendo que destes, três quartas partes militam exclusivamente na lavoura.

Pouco mais da quarta parte dos empresários (27\%) exerceram atividades comerciais e hoteleiras, sendo que a quase totalidade deste grupo de atividades é de comerciantes.

Já aqueles que iniciaram suas atividades profissionais como industriais, alcançaram a $12,4 \%$ do total de empresários, resultado de grande expressão para o contexto do sudoeste paranaense. Acoplados na mesma categoria de atividades, estão incluídos outros doze empresários $(8,7 \%$ do total), que exerceram funções especializadas, tais como: funcionário público ou profissional liberal, dono de posto de gasolina ou de oficina, escultor, técnico vidraceiro e funileiro.

Surge a categoria de operários com alguma especialização, como mecânico, carpinteiro, marceneiro, sapateiro, motorista e seleiro, que totalizam $8,0 \%$ dos atuais empresários. Esta categoria exige um relativo grau de especialização, muito embora as atividades mencionadas no grupo anterior sejam, pelo menos no sudoeste paranaense, de elevado grau de especialização.

$\mathrm{Na}$ derradeira categoria estão apenas $4,4 \%$ dos casos, onde encontramos os operários que de um modo geral não apresentam nenhum grau de especialização. 
Tabela 4

Primeira atividade profissional exercida pelos empresários industriais - 1968

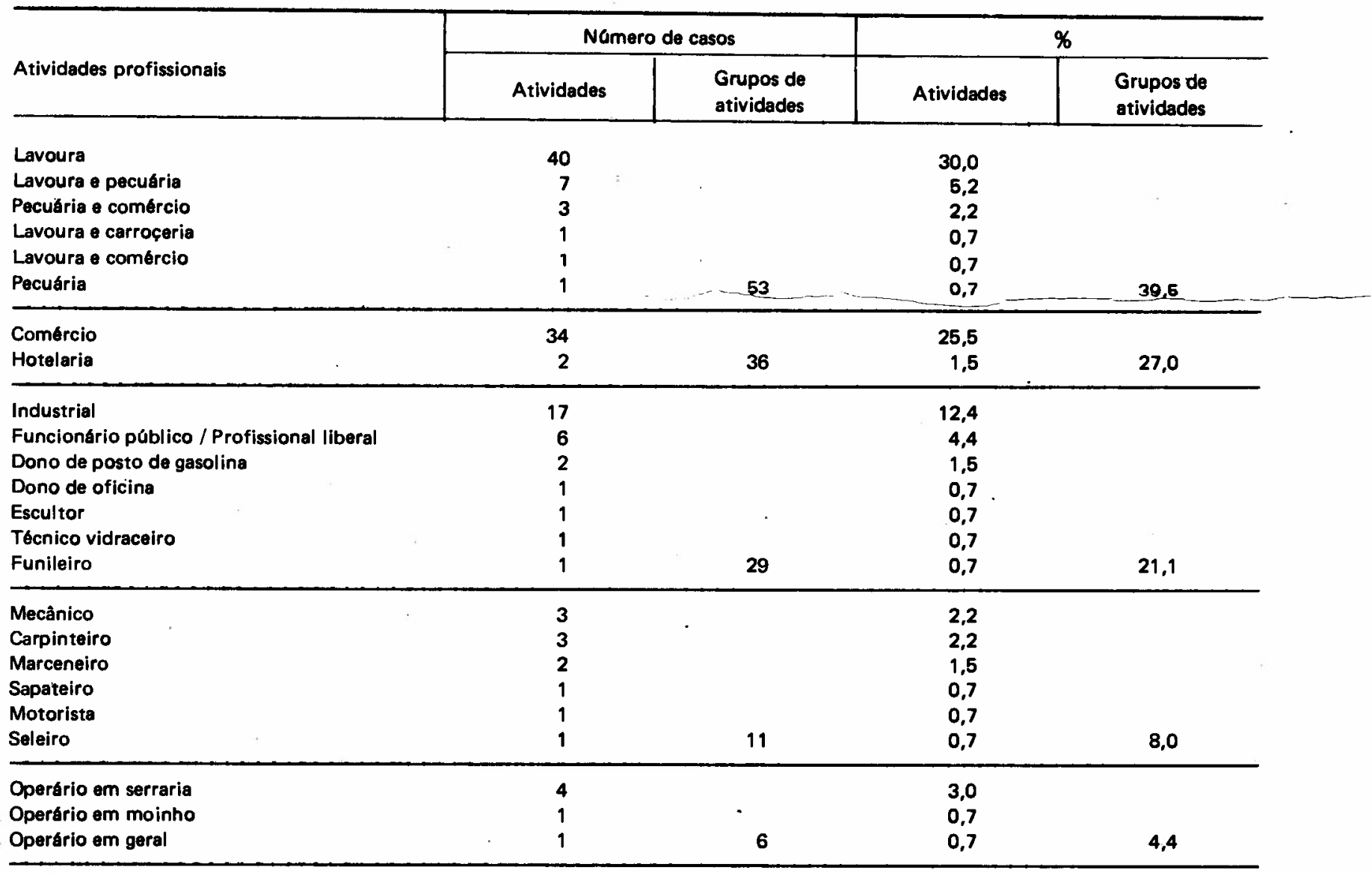

Para estes 135 empresários entrevistados, podemos notar a existência de uma acentuada queda das atividades ligadas à agropecuária - com relação a seus pais - em detrimento de outros setores, principalmente 0 do comércio e o próprio setor industrial, que em termos relativos obteve um substancial aumento.

Devemos ter em mente o quanto é difícil para aqueles que migram ou que exercem pela primeira vez uma atividade ligada ao meio rural, instalar uma indústria em vez de um estabelecimento comercial, fugindo, por vezes radicalmente, dos padrões adquiridos de seus ancestrais.

e) A composição do empresariado - A população do sudoeste paranaense, de origem predominantemente italiana e alemã, e vinda do Rio Grande do Sul e de Santa Catarina, trouxe consigo hábitos e costumes pautados pelo forte sentimento familiar e comunitário. Este, talvez, seja o fator responsável pela elevada participação da família no empresariado industrial.

Em nada menos de $62,2 \%$ dos estabelecimentos industriais, os empresários estão ligados por laços familiares. Em metade destes casos, o empresariado é integralmente constitu fdo por mem- bros de uma mesma família; em $36 \%$ destas indústrias existe uma participação dos membros da família entre dois terços e $40 \%$ do total de empresários; e, nos $14 \%$ restantes destas empresas, existe a participação de duas famílias, sempre representando pelo menos dois terços do total de empresários.

Uma quinta parte das indústrias do sudoeste paranaense é constituída por empresários não ligados por nenhum laço familiar. Estes estabelecimentos possuem em geral, entre apenas dois e três empresários. Uns poucos estabelecimentos possuem maior número de empresários, porém, nunca passando de quinze pessoas. $O$ único estabelecimento que possuía quinze empresários, definia a participação de cada sócio por cotas.

Os estabelecimentos de um único empresário perfazem $15,6 \%$ do total de indústrias do sudoeste paranaense. Há entretanto um estabelecimento industrial que foge integralmente ao padrão de todas as demais empresas. E o caso da Indústria de Oleos Vegetais Sudoeste Sociedade Anônima (IOSSA), que constituiu seu capital mediante duas práticas: $60 \%$ dele foi tomado de empréstimo da Companhia de Desenvolvimento do Estado do Paraná (CODEPAR) e os $40 \%$ restantes através do lança- 
mento de açoses, o que lhe permitiu ter aproximadamente dois mil acionistas, quando da sua instalação.

E esta, evidentemente, a única empresa constituida ao estilo de uma grande indústria, muito embora sua produção se limitasse, na época da pesquisa, ao prensamento de soja e à comercialização do óleo em estado bruto, sem nenhum processo de refino.

\section{CONCLUSĀO}

Vimos que a origem do capital industrial numa região de frente pioneira, no caso o sudoeste paranaense, está nas economias conseguidas a duras penas pelos atuais empresários, seja através do produto agrícola ou do gado vendido, seja através do rendimento auferido de um estabelecimento comercial.
Em um razoável número de casos foi necessária a liquidação de bens patrimoniais, principalmente de terras para levantar o dinheiro; sendo poucos os casos em que o capital tenha-se originado do rendimento de títulos ou do lucro de outros estabelecimentos industriais dos quais os empresários fossem sócios ou mesmo proprietários. Os municipios do sudoeste paranaense são: Ampere, Barracão, Capanema, Chopinzinho, Coronel Vivida, Dois Vizinhos, Enéas Marques, Francisco Beltrão, Itapejara d'Oeste, Maribpolis, Marmeleiro, Pato Branco, Pérola do Oeste, Planalto, Realeza, Renascença, Salgado Filho, Salto do Lontra, Santa Isabel do Oeste, Santo Antonio do Sudoeste, São João, Sã́o Jorge do Oeste, Verê e Vitorino.

NÃO IMPORTA ONDE VOCÊ ESTEJA NOSSAS PUBLICAÇÕES CHEGAM ATÉ VOCÊ.

Basta pedir pelo Reembolso Postal Editora da FGV - Praia de Botafogo, 190

CP 9052 - ZC-02 - Rio de Janeiro

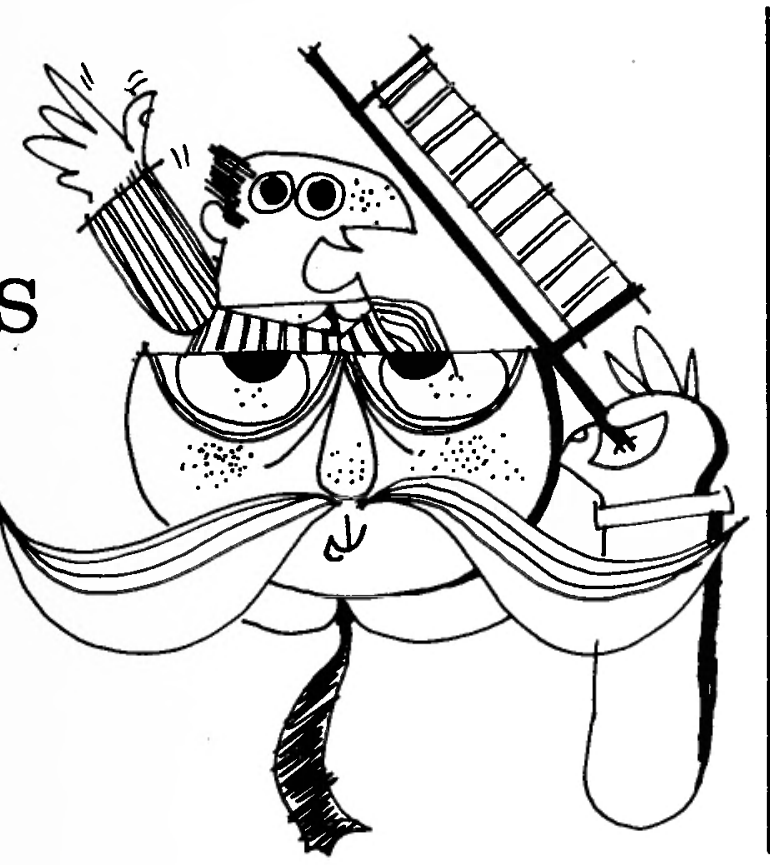

